\title{
Toward a Better Understanding of the Reciprocal Relations Between Adolescent Psychological Need Experiences and Sleep
}

Personality and Social Psychology Bulletin 2021, Vol. 47(3) 377-394 (C) 2020 by the Society for Personality and Social Psychology, Inc Article reuse guidelines: sagepub.com/journals-permissions DOI: $10.1|77 / 0| 46 \mid 67220923456$ journals.sagepub.com/home/psp (S)SAGE

\author{
Rachel Campbell' $\odot$, Maarten Vansteenkiste ${ }^{2}$, Bart Soenens ${ }^{2}$, \\ Beatrijs Vandenkerckhove ${ }^{2}$, and Athanasios Mouratidis ${ }^{3}$
}

\begin{abstract}
In two diary studies, we examined the reciprocal daily association between the satisfaction and frustration of adolescents' basic psychological needs and sleep, and the role of stress and fatigue in these associations. In Study I ( $N=2$ II; $52 \%$ female; Mage $=$ I5.86 years, $S D=1.18$ years), daily need experiences were unrelated to daily fluctuations in subjective sleep outcomes. However, shorter daily sleep quantity was related to higher daily fatigue, which in turn related to more daily need frustration and less need satisfaction. Study $2(N=51 ; 49 \%$ female; Mage $=15.88$ years, $S D=2.88$ years) extended these findings by demonstrating that daily need frustration related to shorter objective sleep quantity and longer wake after sleep onset, indirectly through higher symptoms of stress. Poor sleep quality also related to worse need experiences via higher daily fatigue. These findings underscore the dynamic interplay between daily need experiences and adolescent sleep.
\end{abstract}

Keywords

self-determination theory, basic psychological needs, sleep, adolescence, stress

Received March 06, 20I8; revision accepted April 03, 2020

Adolescence marks a developmental period in which various biological and psychosocial factors conspire to put adolescents at risk of poor sleep (Becker et al., 2015). Early school start times conflict with a biologically driven circadian phase delay that leads adolescents to prefer later bed and wake times (Dahl \& Lewin, 2002), a problem which is further compounded by high academic and extracurricular demands outside of school hours (Miller et al., 2008; Roberts et al., 2011; Zhou et al., 2012). As a result, sleep disturbances in adolescence are highly prevalent, and up to $36 \%$ of adolescents worldwide are estimated to suffer from sleep difficulties (Gradisar et al., 2011). These high prevalence rates are troubling, given that poor sleep in adolescence has been linked to numerous adverse outcomes, including poor academic functioning, mental health problems (e.g., depressive symptoms and low self-esteem), and increased risk of substance use (for an overview, see Shochat et al., 2014).

Apart from adolescence being a vulnerability period for poor sleep, it is also a developmental period during which affective experiences fluctuate strongly on a daily basis. Indeed, adolescents have been shown to display more daily variation in emotions and interaction patterns compared with both younger children and adults (Granic et al., 2003; Larson et al., 2002; Maciejewski et al., 2015), which is likely to have implications for their sleep from day-to-day. The few previous diary studies that have examined adolescent sleep using a dynamic, daily perspective (e.g., Doane \& Thurston, 2014; Fuligni \& Hardway, 2006) indicate that there is striking within-person (i.e., day-to-day) variability in adolescent sleep. This raises the question of which psychological factors and processes lie at the source of this daily variation.

Experiences of the satisfaction and frustration of the basic psychological needs for autonomy, competence, and relatedness, as conceived within self-determination theory (SDT; Ryan \& Deci, 2017), are likely candidates that may account for within-person variability in adolescent sleep because they

\footnotetext{
'University of Sydney, New South Wales, Australia

${ }^{2}$ Ghent University, Belgium

${ }^{3}$ Bilkent University, Ankara, Turkey

Corresponding Author:

Rachel Campbell, School of Psychology, Faculty of Science, University of Sydney, Level 6, Chris O'Brien Lifehouse (C39Z), Sydney, New South Wales 2006, Australia.

Email: r.campbell@sydney.edu.au
} 
have previously been shown to (a) be associated with sleep outcomes (e.g., Campbell et al., 2015, 2019; Campbell, Vansteenkiste, et al., 2018), (b) fluctuate substantially from day-to-day (Ryan et al., 2010), and (c) relate to adolescent adjustment more broadly (e.g., Costa et al., 2016; Mabbe et al., 2016). Furthermore, because both need-based experiences and sleep fluctuate from day-to-day, they are also likely to be reciprocally related to one another (Campbell, Vansteenkiste, et al., 2018). However, little is known about the reciprocal association between psychological needs and the physical need for sleep. Thus, the present research aimed to examine the day-to-day covariation between experiences of satisfaction and frustration of the basic psychological needs for autonomy, competence, and relatedness and adolescent sleep-related outcomes.

\section{SDT: Basic Psychological Needs}

SDT (Deci \& Ryan, 2000; Ryan \& Deci, 2017) is a broad theory of human behavior and personality development, which delineates the necessary conditions for human thriving. Central to SDT is the identification of three inherent and universal basic psychological needs. The need for autonomy refers to experiencing a sense of volition and selfendorsement in one's behavior, the need for competence refers to feeling capable of achieving desired outcomes, and the need for relatedness refers to experiencing a sense of reciprocal care and closeness with important others. Within SDT, the satisfaction of these needs is claimed to be essential for psychological growth and well-being, whereas the active frustration of these needs is said to undermine individuals' functioning and bring about maladaptive outcomes (Vansteenkiste \& Ryan, 2013). When these needs are frustrated, people experience pressure to think, feel, or act a certain way (autonomy frustration); failure and inadequacy (competence frustration); and rejection and social exclusion (relatedness frustration).

Supporting SDT's claims, ample previous research has shown the satisfaction of these basic psychological needs to be associated with a host of adaptive outcomes. For example, when these psychological needs are satisfied, people report higher levels of subjective vitality (Ryan \& Deci, 2008), self-esteem, and life satisfaction (Deci \& Ryan, 2000). Associations between need satisfaction and indicators of wellness have emerged across diverse life domains (such as work, education, sport, and health care), age groups (Heisel et al., 2018), and cultures (e.g., Chen et al., 2015).

Importantly, although low need satisfaction can hamper psychological well-being, recent theoretical developments in SDT (Ryan \& Deci, 2017; Vansteenkiste et al., in press; Vansteenkiste \& Ryan, 2013) and empirical studies suggest that the active frustration or undermining of psychological needs is likely to be especially damaging and a more robust predictor of ill-being. In particular, recent claims state that a lack of need satisfaction does not necessarily signify the presence of need frustration. Rather, need frustration only occurs when psychological needs are actively undermined or thwarted. To illustrate, an adolescent may not feel particularly close or connected to a peer or their teacher (i.e., low need satisfaction) but that does not necessarily mean that they feel actively excluded or rejected by that person (i.e., relatedness frustration), with the latter being more likely to bring about maladaptive functioning.

In accordance with these claims, a rapidly growing number of studies have shown psychological need frustration to uniquely predict maladaptive outcomes such as symptoms of anxiety and somatization (Cordeiro et al., 2016) as well as depressive symptoms and exhaustion (Bartholomew et al., 2011), over and above a lack of need fulfillment. These findings are consistent with the notion that need satisfaction is especially involved in fostering adaptive functioning, whereas need frustration plays a critical role in eliciting maladaptive functioning (Ryan et al., 2016; Vansteenkiste \& Ryan, 2013).

Although much of this previous research was carried out among adults, several studies have also begun to demonstrate the importance of these psychological needs for adolescents' adjustment. Specifically, previous studies indicate that need satisfaction contributes to adolescents' well-being and resilience (Emery et al., 2015; Véronneau et al., 2005), whereas need frustration poses risk of distress and problem behaviors (Costa et al., 2016; Mabbe et al., 2016).

Furthermore, need-based experiences have also been shown to vary substantially from day-to-day, with daily variation in need experiences predicting daily variation in well-being (Ryan et al., 2010). Surprisingly, few studies to date have examined daily fluctuations in adolescents' need experiences (see Verstuyf et al., 2013, for an exception). This is unfortunate because adolescents have been shown to display variable emotions from day-to-day (Granic et al., 2003; Larson et al., 2002; Maciejewski et al., 2015), suggesting that they are also likely to display considerable ups and down in need experiences on a daily basis, which may affect their sleep.

\section{Bidirectional Relations Between Basic Psychological Needs and Sleep}

Apart from these basic psychological needs being robustly related to indicators of well-being (when satisfied) and illbeing (when frustrated), a few studies also suggest that they play a role in the (dys)regulation of physiological needs such as sex (Smith, 2007) and eating behavior (Boone et al., 2014). Importantly, psychological needs have also been implicated in individuals' sleep quantity, which refers to the total amount of time an individual sleeps per night, and subjective sleep quality, which refers to a person's subjective appraisal of the quality of their previous nights' sleep. For example, one study examining between-person differences among healthy adults found that individuals who 
experienced higher need satisfaction during the past month also reported better subjective sleep quality and somewhat longer sleep duration (Campbell et al., 2015). Similarly, another cross-sectional study demonstrated need satisfaction to be related to better subjective sleep quality among HIV patients (Campbell et al., 2019). Of particular relevance to the present study, a recent diary study among patients with chronic fatigue syndrome (CFS), who are especially at risk of poor sleep, demonstrated that daily need frustration preceded poorer quality sleep at night (Campbell, Vansteenkiste, et al., 2018). Together, these previous findings indicate that need-based experiences relate to diverse sleep outcomes, and suggest that their relation with subjective sleep quality in particular is more pronounced. However, despite previous evidence suggesting that psychological need experiences may contribute to day-to-day variability in subjective sleep quality, no studies have yet examined whether these within-person associations also extend to adolescent populations.

A few previous studies provide indirect support for the hypothesized day-to-day (i.e., within-person) association between SDT's basic psychological needs and sleep-related outcomes among adolescents. For example, a diary study among adolescents (aged 14-15), found that higher daily academic demands were associated with less self-reported sleep at night (Fuligni \& Hardway, 2006), whereas another diary study among first-year university students (aged 17-19) demonstrated that expecting to take a test the next day was associated with shorter self-reported sleep quantity (Galambos et al., 2009). Indeed, high academic demands and expecting to take a test the next day may be accompanied by feelings of both autonomy and competence frustration because some adolescents might feel pressured to do their school work (e.g., by their teachers or parents) at the expense of engaging in other "more fun" activities, and may also have doubts about their capabilities to meet external requirements and to achieve desired grades (see Krijgsman et al., 2017). In addition, there is also evidence to suggest that experiences of relatedness are implicated in daily variability in adolescent sleep. For example, Galambos et al. (2009) demonstrated that socializing with friends during the day was associated with longer self-reported sleep duration. Furthermore, another diary study, utilizing objective measures of sleep, found that adolescents (age 17-18) higher in trait loneliness slept less across a 3-day study period (Doane \& Thurston, 2014). Although these studies did not directly assess SDT's basic psychological needs, together they provide indirect evidence for the hypothesis that experiences of the satisfaction and frustration of psychological needs may be implicated in the day-to-day variability in adolescent sleep.

Of course, it is equally plausible that daily need experiences not only precede but may also follow from sleep at night. Indeed, previous diary studies among adolescents provided evidence for the role of daily quality and quantity of sleep in contributing to daily experiences. For example,
Fuligni and Hardway (2006) found that shorter selfreported sleep duration was related to more fatigue and feelings of anxiety and depressive symptoms throughout the following day. In addition, Galambos et al. (2009) found that less self-reported sleep at night contributed to more negative affect and less socializing with friends the next day, whereas poorer subjective sleep quality was related to more negative affect and less positive affect.

Much like sleep affects adolescents' emotions, sleep is also likely to influence adolescents' need-based experiences. Because of sleep's restorative and energizing properties, after a night of sufficient, good-quality sleep, adolescents are likely to feel less fatigued, which may facilitate their effective engagement in need-satisfying activities. Thus, we propose that daily experiences of the satisfaction and frustration of basic psychological needs are likely to be reciprocally related to the physical need for sleep, albeit indirectly through (i.e., mediated by) daily fluctuations in fatigue. In line with this reasoning, a recent diary study among CFS patients demonstrated that poorer subjective sleep quality at night was predictive of lower subjective energy the following day (i.e., higher fatigue and lower vitality), which then, in turn, related to less need satisfaction and more need frustration throughout the day (Campbell, Vansteenkiste, et al., 2018). Furthermore, an experimental study conducted among a group of healthy adults demonstrated that participants who were partially sleep deprived reported reduced need satisfaction after 3 days of impaired sleep (Campbell, Soenens, Weinstein, \& Vansteenkiste, 2018). Although these studies were not conducted among adolescents, they provide some evidence that sleep at night may both predict and be predicted by the satisfaction or frustration of adolescents' basic psychological needs via fluctuations in daily fatigue.

\section{The Role of Stress}

In addition to examining the reciprocal day-to-day association between need experiences and sleep, a second main objective of the present research was to examine processes that account for (i.e., explain) the hypothesized need-sleep relation. In the present research, we propose that symptoms of stress such as tension and arousal (Lovibond \& Lovibond, 2004) may play an explanatory role in these day-to-day associations. This is because symptoms of stress likely arouse adolescents to a level that makes it difficult to relax at night, thereby obstructing restful sleep. In support of this view, a longitudinal study found that older adolescents (aged 17-19) reported poorer subjective sleep quality and shorter sleep duration in months that they experienced higher stress (Galambos et al., 2010). In addition, diary studies have shown perceived stress during the day to predict shorter subjectively reported (Fuligni \& Hardway, 2006) and objectively recorded (Doane \& Thurston, 2014) sleep duration. 
Although previous research suggests that daily stress is detrimental to adolescent sleep, no studies have yet identified specific factors within the day that contribute to this dayto-day variability in stress and in turn poor sleep. In the present research, we propose that on days that adolescents experience low satisfaction or even frustration of their basic psychological needs and thus feel pressured and ineffective in their activities and rejected by important others, they are likely to experience more symptoms of stress (e.g., tension and arousal). In turn, stress likely obstructs both the quality and quantity of their sleep at night.

In line with this reasoning, several previous studies (conducted mainly with adults) suggest that basic psychological needs are involved in stress reactivity, with psychological need frustration, in particular, being associated with experienced stress (for an overview, see Weinstein \& Ryan, 2011). For example, a recent study among individuals with unexplained chronic fatigue demonstrated that participants who experienced more need frustration during the past week reported more symptoms of stress and negative sleeprelated thoughts, which in turn contributed to poorer quality and quantity of sleep during a stay at a sleep laboratory (Campbell et al., 2017). Furthermore, a short-term longitudinal study with college students found that increases in psychological need frustration related to increases in symptoms of stress, which in turn related to deterioration in quality and quantity of sleep (Campbell, Soenens, Beyers, \& Vansteenkiste, 2018). However, no studies have yet examined the intervening role of stress in the relation between daily psychological need experiences and adolescent quality and quantity of sleep.

In addition to symptoms of stress predicting poor sleep, we also acknowledge that the reverse pathway is equally plausible; specifically, that poor sleep at night may predict symptoms of stress the next day. In line with this reasoning, a number of previous studies have shown poor sleep to predict daily stress (e.g., Hisler et al., 2019; Yap et al., 2019), presumably because sleep disturbance lowers an individual's capacity to cope with daily stressors, which in turn may perhaps interfere with their responsiveness to opportunities for need satisfaction and exacerbate need frustration throughout the day. Thus, in addition to fatigue, it is equally plausible that symptoms of stress may also play an intervening role in the association between adolescents' sleep at night and their need-based experiences throughout the following day.

\section{Present Research}

The global objective of the present research was to examine the day-to-day association between psychological need experiences and quality and quantity of sleep among adolescents. To investigate these dynamic associations, we conducted two diary studies. This allowed for the close examination of lived day-to-day experiences in a natural context, thereby increasing the ecological validity of the findings. Furthermore, because participants provided assessments every day, measurement error due to biased retrospective recall was minimized (Bolger et al., 2003).

Given the lack of previous studies examining the role of need experiences in contributing to adolescent sleep and vice versa, our first main objective was to examine the hypothesized reciprocal need-sleep dynamics at the within-person level (i.e., from day-to-day). Specifically, in both studies, we examined whether a composite score of the satisfaction and frustration of daily need experiences would predict and be predicted by quality and quantity of sleep. In Study 1, we began by examining these associations using daily selfreports. However, given that (a) a sole reliance on selfreports can inflate associations due to shared method variance and (b) adolescent self-reports tend to inaccurately estimate quantitative sleep indicators, such as sleep latency, wake after sleep onset, and sleep duration (Tremaine et al., 2010), we sought to overcome this problem in Study 2 by assessing sleep objectively using wrist actigraphy. In addition, in both studies, we also explored the unique role of each individual need satisfaction and frustration (i.e., for autonomy, competence, and relatedness) in these reciprocal associations. However, we had no specific hypotheses regarding their differential role in these reciprocal associations as SDT regards each of the three needs to be essential for optimal functioning and well-being (Ryan \& Deci, 2017).

The second key objective of the present research was to examine the explanatory processes that would intervene in the hypothesized bidirectional needs-sleep relation. The role of both fatigue and symptoms of stress was examined in the association between sleep and need-based experiences, whereas only the role of symptoms of stress was considered in the association between psychological need experiences and the sleep-related outcomes. The explanatory role of fatigue was addressed in both studies, whereas the question of whether symptoms of stress would account for (i.e., explain) the day-to-day association between psychological need experiences and sleep and vice versa was only addressed in Study 2. Of note, given that (a) the present research is the first to examine reciprocal day-to-day (i.e., within-person) associations between basic psychological needs and sleep among adolescents and (b) equivalent previous studies are considered necessary to conduct a power analysis (Levine \& Ensom, 2001), we were unable to rely on effect sizes from prior studies to perform an a priori power analysis.

\section{Study I}

In Study 1, we tested two hypotheses. First, we examined whether day-to-day variability in need satisfaction and need frustration would account for variation in daily quality and quantity of sleep at night (Hypothesis 1). We hypothesized that adolescents who encounter more need frustrating experiences during a given day would report poorer quality and shorter 
quantity of sleep at night, because these negative experiences would likely elicit emotional and physiological arousal, which would obstruct restful sleep at night. The opposite pattern was expected for daily variation in need satisfaction, which may facilitate better quality and quantity of sleep from day-to-day.

Second, we examined whether night-to-night variability in quality and quantity of sleep would contribute to adolescents' need experiences throughout the following day. The reason why poorer quality and quantity of sleep may obstruct adolescents' need-based experiences is because poor sleep is likely to drain adolescents of energy, which would manifest as higher fatigue. This enhanced fatigue would then hinder adolescents' effective engagement in need-satisfying activities, thereby contributing to lower daily need satisfaction and higher daily need frustration.

\section{Method}

Participants and procedure. Participants were 211 Belgian adolescents $(52 \%$ female, Mage $=15.86$ years, $S D=1.18$ years, range $=13-18$ years). All participants were enrolled in a secondary education with $64 \%$ following a general academic track, $27 \%$ following a technical track, $7 \%$ following a vocational track, and $2 \%$ following an artistic track.

All participants were recruited by second-year bachelor students from Ghent University as part of an undergraduate course in developmental psychology. All bachelor students were asked to recruit two adolescents for the study and received clear instructions regarding the recruitment procedure. Participants were visited at their home, during which the requirements of the study were explained and written informed consent was obtained from all participants as well as from their parents. Participation in the study was voluntary and confidential treatment of the data was guaranteed. During the first home visit, participants received a booklet with daily questionnaires, which they were asked to fill in twice a day for eight consecutive days, once in the evening directly before going to bed and once in the morning directly after waking up. All participants completed the diaries on the same days of the week, from a Monday to a Monday and were sent daily reminders in the form of an email or text message to stimulate ongoing completion of the diaries. During a second home visit, the diaries were collected by the bachelor students who then returned them to the researchers. The procedure was carried out conform to the ethical guidelines at Ghent University.

Daily measures. The reliability of the daily measures was estimated using the procedure outlined by Geldhof et al. (2014). Within- and between-level alphas are reported for each daily measure.

\section{Daily evening measures}

Daily psychological need satisfaction and need frustration. The daily satisfaction and frustration of the basic psychological needs for autonomy, competence, and relatedness were assessed using the Balanced Measure of Psychological Needs (BMPN; Sheldon \& Hilpert, 2012). The scale consists of 18 items, six items per need, three of which tap into need satisfaction and three of which tap into need frustration, and was adapted so that it assessed experiences during the past day. All participants rated on a scale of 1 (not at all true) to 5 (very true) as to whether they felt their need for autonomy (e.g., "Today the activities that I engaged in were based on my true interests and values" or "Today I had a lot of pressures I could do without"), competence (e.g., "Today I successfully completed difficult tasks and projects" or "Today I experienced some kind of failure, or was unable to do well at something"), and relatedness (e.g., "Today I felt close and connected to the people who are important to me" or "I was lonely") were satisfied or frustrated during the past day. Two composite scores were created by averaging the nine items assessing daily need satisfaction (within-person $\alpha=.71$, betweenperson $\alpha=.93$ ) and by averaging the nine items assessing daily need frustration (within-person $\alpha=.63$, between-person $\alpha=.90$ ). Satisfaction of the needs for autonomy (withinperson $\alpha=.67$, between-person $\alpha=.90$ ), competence (within-person $\alpha=.60$, between-person $\alpha=.87$ ), and relatedness (within-person $\alpha=.76$, between-person $\alpha=.96$ ) had acceptable reliability. Frustration of the needs for autonomy (within-person $\alpha=.49$, between-person $\alpha=.80$ ), competence (within-person $\alpha=.57$, between-person $\alpha=.85$ ), and relatedness (within-person $\alpha=.51$, between-person $\alpha=.83$ ) yielded poor reliability at the within-person level.

Daily fatigue. Daily fatigue was assessed using the Lassitude subscale from the Inventory of Depression and Anxiety Symptoms (IDAS; Watson et al., 2007). The six-item scale was adapted to assess symptoms of fatigue experienced during the past day (e.g., "Today I felt sleepy and drowsy"). All items were rated on a 5-point Likert-type scale ranging from 1 (not at all) to 5 (very much so). The scale had good reliability (within-person $\alpha=.84$, between-person $\alpha=.91$ )

\section{Daily morning measures}

Daily subjective sleep quality. Daily subjective sleep quality was assessed using a visual analogue scale (VAS) from the Pittsburgh Sleep Diary (Monk et al., 1994). All participants rated a VAS that assessed their previous night's subjective sleep quality (i.e., "How was your sleep quality last night?") on a scale from 0 (extremely poor) to 100 (extremely good).

Daily sleep quantity. Daily sleep quantity was calculated using four open-ended questions from the Pittsburgh Sleep Diary (Monk et al., 1994), which assessed evening bed-time, morning wake-time, number of minutes it took to fall asleep (sleep latency), and the number of minutes spent awake during the night after initial sleep onset (wake after sleep onset). Total time in bed was calculated on the basis of the bed and wake times. Daily sleep duration was then calculated by subtracting sleep latency and wake after sleep onset from the total time spent in bed. 
Table I. Means, Standard Deviations, ICCs, and Within-Person and Between-Person Correlations Between Study Variables-Study I.

\begin{tabular}{|c|c|c|c|c|c|c|c|c|c|c|c|c|c|}
\hline Study Variables & I & 2 & 3 & 4 & 5 & 6 & 7 & 8 & 9 & 10 & II & 12 & 13 \\
\hline $\begin{array}{l}\text { I. Need satisfaction } \\
\text { composite }\end{array}$ & - & $.88 * *$ & $.82 * *$ & $.82 * *$ & $-.19 * *$ & -.11 & $-.15^{*}$ & $-.21^{* *}$ & $-.23 * *$ & $.26 * *$ & $.19 * *$ & -.09 & -.004 \\
\hline $\begin{array}{l}\text { 2. Autonomy } \\
\text { satisfaction }\end{array}$ & $.83 * *$ & - & $.65^{* *}$ & $.58 * *$ & $-.23^{* *}$ & $-.19 * *$ & $-.15^{*}$ & $-.23 * *$ & $-.24^{* *}$ & $.28 * *$ & $.18^{* *}$ & -.08 & -.03 \\
\hline $\begin{array}{l}\text { 3. Competence } \\
\text { satisfaction }\end{array}$ & $.76 * *$ & $.50 * *$ & - & $.45^{* *}$ & -.06 & .02 & -.06 & -.09 & $-.19 * *$ & .12 & $.15^{*}$ & -.13 & -.03 \\
\hline $\begin{array}{l}\text { 4. Relatedness } \\
\text { satisfaction }\end{array}$ & $.76 * *$ & $.44^{* *}$ & $.34 * *$ & - & $-.20 * *$ & -.11 & $-.17 *$ & $-.21^{*}$ & $-.14^{*}$ & $.25 * *$ & $.15^{*}$ & -.03 & .04 \\
\hline $\begin{array}{l}\text { 5. Need frustration } \\
\text { composite }\end{array}$ & $-.25^{* *}$ & $-.28^{* *}$ & $-.10 * *$ & $-.20 * *$ & - & $.85^{* *}$ & $.83^{* *}$ & $.85^{* *}$ & $.57 * *$ & $-.35^{* *}$ & $-.21^{* *}$ & .01 & .13 \\
\hline $\begin{array}{l}\text { 6. Autonomy } \\
\text { frustration }\end{array}$ & $-.17^{* *}$ & $-.25^{* *}$ & -.04 & $-.10 * *$ & $.83^{* *}$ & - & $.61^{* *}$ & $.59 * *$ & $.46^{* *}$ & $-.27 * *$ & $-.19 * *$ & .05 & $.15^{*}$ \\
\hline $\begin{array}{l}\text { 7. Competence } \\
\text { frustration }\end{array}$ & $-.19 * *$ & $-.19 * *$ & $-.11 * *$ & $-.14 * *$ & $.78^{* *}$ & $.5 \mathrm{I} * *$ & - & $.55^{* *}$ & $.52 * *$ & $-.32 * *$ & $-.18^{* *}$ & .05 & .03 \\
\hline $\begin{array}{l}\text { 8. Relatedness } \\
\text { frustration }\end{array}$ & $-.23^{* *}$ & $-.21^{* *}$ & $-.10 * *$ & $-.23 * *$ & $.77^{* *}$ & $.4 I^{* *}$ & $.39 * *$ & - & $.49 * *$ & $-.32^{* *}$ & $-.16^{*}$ & -.06 & $.15^{*}$ \\
\hline 9. Fatigue & $-.20 * *$ & $-.23^{* *}$ & $-.14^{* *}$ & $-.1 \mathrm{I} * *$ & $.43^{* *}$ & $.36^{* *}$ & $.37 * *$ & $.30 * *$ & - & $-.32 * *$ & $-.15^{*}$ & .08 & $.14^{*}$ \\
\hline $\begin{array}{l}\text { 10. Subjective sleep } \\
\text { quality }\end{array}$ & $.15^{* *}$ & $.14^{* *}$ & $.09 * *$ & $.1 \mathrm{I} * *$ & $-.20 * *$ & $-13^{* *}$ & $-.16 * *$ & $-.18^{* *}$ & $-.12^{* *}$ & - & $.20 * *$ & -.28 & -.10 \\
\hline $\begin{array}{l}\text { II. Subjective sleep } \\
\text { quantity }\end{array}$ & $.08 * *$ & .10 ** & .06 & .02 & $-.13^{* *}$ & $.12^{* *}$ & $-.11 * *$ & $-.07^{* *}$ & -.06 & $0.20 * *$ & - & -.13 & $-.16^{*}$ \\
\hline $\begin{array}{l}\text { 12. Subjective sleep } \\
\text { latency }\end{array}$ & -.02 & -.05 & -.04 & .02 & .03 & $.08 * *$ & .06 & -.06 & .01 & $-.29 * *$ & $-.23 * *$ & - & $.21 * *$ \\
\hline $\begin{array}{l}\text { 13. Subjective wake } \\
\text { after sleep onset }\end{array}$ & .01 & -.004 & .03 & .00 & .05 & .04 & .05 & -.01 & .03 & $-.36 * *$ & $-.25^{* *}$ & $.27 * *$ & - \\
\hline M & 3.36 & 3.24 & 2.99 & 3.84 & 1.97 & 2.19 & 1.84 & 1.88 & 2.21 & 67.31 & 501.86 & 19.41 & 5.79 \\
\hline$S D$ & 0.73 & 0.97 & 0.88 & 0.96 & 0.70 & 0.95 & 0.79 & 0.89 & 0.94 & 26.36 & 94.31 & 20.61 & 15.8 \\
\hline ICC & .48 & .33 & .42 & .46 & .51 & $.4 \mathrm{I}$ & .43 & .39 & .27 & .32 & .14 & .39 & .11 \\
\hline
\end{tabular}

Note. Within-person correlations are displayed below the diagonal and between-person correlations are displayed above the diagonal. ICC $=$ intraclass correlations.

$*_{p}<.05 . *_{p}<.01$.

Plan of analysis. As this study involved repeated measurements on eight consecutive days (i.e., Level 1) nested within 211 adolescents (i.e., Level 2), multilevel analyses were performed using Mplus 7 to take both between- and withinperson differences into account. All predictor variables at Level 1 were group-mean centered. There were only eight cases with missing values on all variables and another 11 cases with missing values on at least one of the measured variables (1.1\% missing values in total). Little's missing completely at random (MCAR) test (i.e., $n=11$ ) was significant, $\chi^{2}(13)=66.17, p<.001$, indicating that the data were unlikely to be missing at random Further analysis showed that the null hypothesis, which assumes missingness at random, was rejected due to the fatigue variable. Little's MCAR test for a reduced dataset that only included need satisfaction, need frustration, subjective sleep quality, and sleep quantity was nonsignificant, $\chi^{2}(8)=11.44, p=.18$. As a result, full information maximum likelihood (FIML) was used to handle missing data in the two-level path models (structural equation modeling [SEM]; Little \& Rubin, 1987).

Prior to investigating our main hypotheses, we began by examining whether there was significant day-to-day variability in the study variables by estimating interceptonly models without any explanatory variables. These models decompose the total variation in each outcome into variation at the between- and the within-person level. Then, a two-level path model was tested in which we examined whether daily variation in evening reports of need satisfaction and need frustration would relate to quality and quantity of sleep, as reported in the morning (Hypothesis 1). Next, we tested a second two-level path model in which we examined whether daily variability in quality and quantity of sleep, as reported in the morning, would contribute to experiences of need satisfaction and need frustration as reported in the evening of the same day through (i.e., mediated by) experiences of fatigue that day (Hypothesis 2).

\section{Results}

\section{Preliminary analyses}

Correlations. The means, standard deviations, and correlations between the assessed measures are shown in Table 1. At both, the between- and within-person levels, the composite scores of daily need satisfaction related negatively to 
daily fatigue and positively to daily quality and quantity of sleep; the opposite pattern was found for the composite scores of daily need frustration. The three separate need satisfactions and need frustrations (i.e., for autonomy, competence, and relatedness) were moderately to strongly correlated within one another and displayed a similar pattern of relations with the study variables.

Background variables. To examine the relation between adolescents' background characteristics and the study variables, we aggregated all daily measures across the 8 days. Then, a multivariate analysis of covariance (MANCOVA) was performed with gender as a fixed factor, age as a covariate, and all study variables as dependent variables. Gender did not yield a significant multivariate effect, $F(5,203)=$ $1.81, n s$, whereas age did, $F(5,203)=3.30, p<.01$, $\eta^{2}=.08$. Subsequent univariate analyses indicated that age was positively related to need frustration, $F(1,207)=4.76$, $p<.05, \eta^{2}=.02$, and negatively related to both daily quality, $F(1,207)=4.00, p<.05, \eta^{2}=.02$, and quantity, $F(1,207)=12.62, p<.01, \eta^{2}=.06$, of sleep.

Intraclass correlations (ICCS). The ICC values for each study variable are also displayed in Table 1 . With regard to fatigue and the sleep outcomes, the ICC values indicated that a significant proportion of the variance in these variables was situated at the within-person level, with subjective wake after sleep onset displaying the most variance within individuals (i.e., approx. 89\%) and subjective sleep latency displaying the least amount of variance within individuals (i.e., approx. 61\%). With regard to need-based experiences, ICC values indicated that approximately $52 \%$ and $49 \%$ of the variance in need satisfaction and need frustration, respectively, was situated within individuals (i.e., from day-today). Thus, overall, these results revealed considerable fluctuations in the study variables across the 8-day period, justifying our multilevel analytical approach.

\section{Primary analyses}

Hypothesis 1: The role of daily psychological need experiences in predicting daily subjective sleep outcomes.

First, we began by examining whether composite scores ${ }^{1}$ of daily need satisfaction and need frustration would predict day-to-day variation in sleep. A two-level path model was specified in which paths were added at the within-person level (i.e., daily level) from need satisfaction and need frustration to the subjective sleep outcomes (i.e., subjective sleep quality, sleep latency, sleep quantity, and wake after sleep onset), which were allowed to correlate. Results of this model, comparative fit index $(\mathrm{CFI})=0.93$, root mean square error of approximation $($ RMSEA $)=0.05$, standardized root mean square residual (SRMR; within) $=0.01$, indicated that daily need experiences were unrelated to the sleep outcomes at the within-person level.
Hypothesis 2: The role of daily subjective sleep indicators in predicting need experiences via fatigue.

Next, we tested a model in which we examined whether day-to-day variation in subjective sleep indicators would contribute to daily variability in need satisfaction and need frustration, through (i.e., mediated by) fluctuations in fatigue. First, direct paths were added at the within-person level (i.e., daily level) from the subjective sleep indicators to the need composites (i.e., need satisfaction and need frustration), which were allowed to correlate. Results from this model, $\mathrm{CFI}=0.98$, RMSEA $=0.04$, SRMR (within) $=0.001$, indicated that daily sleep duration was negatively related to daily need frustration $(B=-0.001, \beta=-.10, S E=0.04, p<.01$; confidence interval $[\mathrm{CI}] 95 \%=[-0.157,-0.039])$, whereas daily sleep latency was positively related to daily need frustration $(B=0.004, \beta=.10, S E=0.03, p<.01 ;$ CI $95 \%=$ $[0.048,0.160])$.

Next the role of fatigue as an intervening variable was examined by adding paths from the subjective sleep indicators to fatigue and from fatigue to the need composite scores. Results from this model, CFI $=0.90$, RMSEA $=0.05$, SRMR (within) $=0.03$, indicated that daily subjective sleep quantity was negatively related to daily fatigue $(B=-0.002$, $\beta=-.13, S E=0.03, p<.001 ;$ CI $95 \%=[-0.183$, $-0.085])$. Daily fatigue, in turn, was negatively related to daily need satisfaction $(B=-0.14, \beta=-.29$, $S E=0.04, p<.001$; CI $95 \%=[-0.368,-0.232])$ and positively related to daily need frustration $(B=0.21$, $\beta=.48, S E=0.04, p<.001 ;$ CI $95 \%=[0.392,0.511])$. Direct paths were gradually added in between the predictor variables (i.e., subjective sleep indicators) and the outcomes (i.e., need satisfaction and need frustration) but were removed because they were nonsignificant, with the exception of the direct path between subjective sleep latency and need frustration, which remained significant $(B=0.004$, $\beta=.10, S E=0.03, p<.001$; CI $95 \%=[0.055,0.151]){ }^{2}$ The results from this final integrative model, $\mathrm{CFI}=.91$, RMSEA $=.05$, SRMR (within) $=.03$, are shown in Figure 1.

The indirect associations at the within-person level between daily sleep duration and daily need satisfaction $(B=0.000, S E=0.000, p<.01$; CI $95 \%=[0.000$, $0.000])$ and daily need frustration $(B=0.000, S E=$ $0.00001, p<.01$; CI $95 \%=[-0.001,0.000])$ via daily fatigue were significant. In a next model, we controlled for the previous day levels of fatigue and need experiences. Results from this model indicated that all initially observed within-person associations remained significant (see Figure S1 in the Supplemental Material).

\section{Brief Discussion}

The results from Study 1 indicate that daily fluctuations in adolescents' sleep pattern predicted, but were not predicted by, daily fluctuations in need-based experiences. 


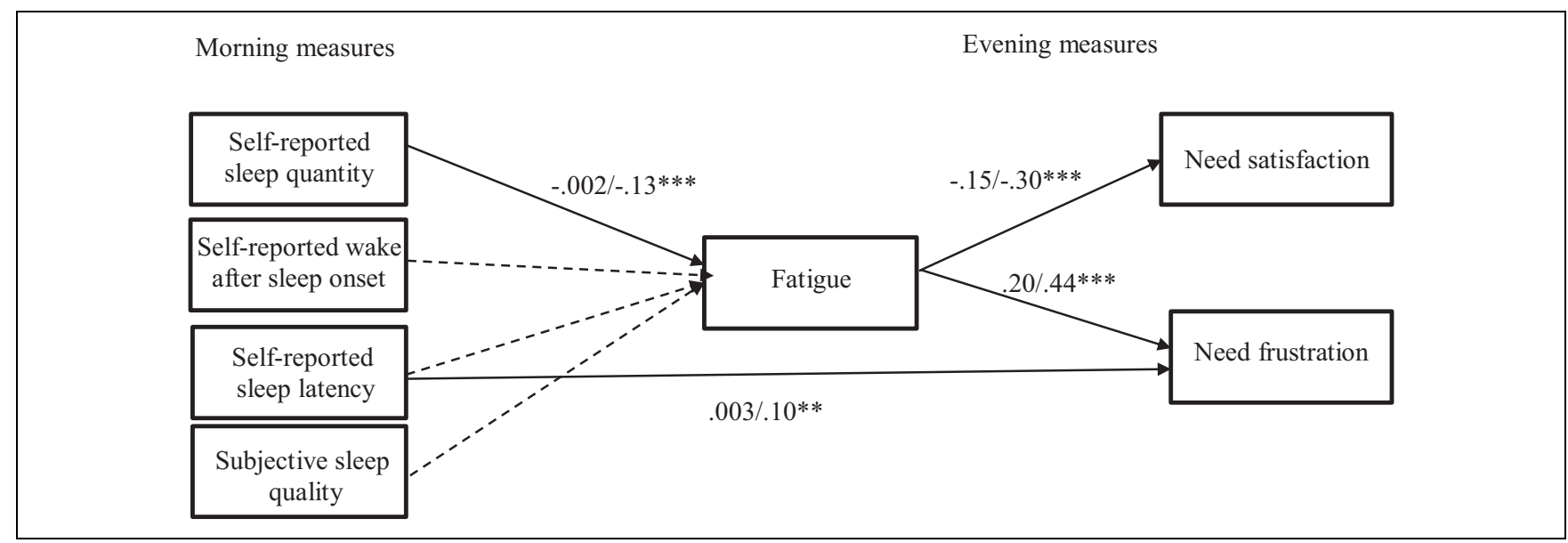

Figure I. Daily subjective sleep indicators predicting daily need satisfaction and need frustration via fatigue-Study I.

Note. Coefficients before the line are unstandardized and coefficients after the line are standardized. Broken lines represent nonsignificant paths. $*_{p}<.05 . * * p<.01 . * * * p<.001$.

Specifically, shorter daily sleep quantity as reported in the morning predicted more fatigue throughout the day, which in turn related to less daily experiences of need satisfaction and more experiences of need frustration. In addition, on days that it took longer to fall asleep at night, adolescents also reported more need frustration the following day, which was not accounted for by higher fatigue. Overall, these results only partially supported our hypotheses by demonstrating that only daily fluctuations in sleep contribute to daily variation in need-based experiences and not vice versa.

\section{Study 2}

Given that the pattern of findings in Study 1 was somewhat variable and because, to the best of our knowledge, this is the first study to address the needs-sleep link in adolescents, the findings are in need of replication. We aimed to build on findings from Study 1 in two important ways: first, by assessing quantitative sleep indicators (i.e., sleep quantity, sleep latency, and wake after sleep onset) objectively from day-today using actigraphy. Actigraphy is a device worn on the wrist that measures movement, and thereby allows for the differentiation between probable wake and sleep states. The data derived from actigraphy enabled us to examine whether the findings observed in Study 1 would also hold when assessing a number of sleep indicators objectively. We deemed this important, because adolescents' self-reports of sleep duration, sleep latency, and wake after sleep onset are subject to misperception (e.g., Tremaine et al., 2010).

Second, we further aimed to extend findings from Study 1 by examining whether perceived stress would play an intervening role in the day-to-day association between need-based experiences and daily sleep. Although daily need-based experiences were not directly related to daily sleep in Study 1, a previous prospective study in a clinical sample found that between-person differences in need-based experiences were indirectly (but not directly) related to subjective and objective sleep indicators via symptoms of stress and negative sleep cognitions (Campbell et al., 2017). As such, based on recent theorizing (Vansteenkiste \& Ryan, 2013) and empirical findings (Campbell et al., 2017; Van der Kaap-Deeder et al., 2016), we hypothesized that on days that adolescents experience higher need frustration, they would report more symptoms of stress, which in turn would obstruct sleep at night, as manifested by shorter sleep time, more awakenings throughout the night, poorer subjective sleep quality, and possibly longer sleep latency on a dayto-day basis. Furthermore, similar to Study 1, we also aimed to examine whether poorer sleep (as indicated by subjective sleep quality and objectively assessed sleep indicators) would contribute not only to more fatigue but also to more symptoms of stress, and in turn, less need satisfaction and more need frustration from day-to-day (Hypothesis 2).

\section{Method}

Participants and procedure. Participants were 51 Belgian adolescents ( $49 \%$ female, Mage $=15.88$ years, $S D=2.88$ years, range $=12-19$ years) who were all enrolled in secondary school education and following a general academic track. Two secondary school principals were contacted and asked whether their school was willing to participate in the study. The principals then posted the study on their school's electronic learning platform; they also encouraged interested teachers to notify the students in their class about the study, and provided the students with an information sheet for their parents. Parents of adolescents who were interested in participating in the study contacted the researchers by email. The researchers then contacted all the adolescents who expressed interest and arranged to visit the school to explain the details and requirements of the study to small groups of students. During this school visit, all adolescents were given an 
informed consent form, a diary, and an actigraph watch, and were made aware of the voluntary and confidential nature of the study. This informed consent form was taken home and signed by both the adolescents themselves and their parents before being returned to the researchers. The students were instructed to wear the actigraph watch for the whole duration of the study (i.e., for the full 7 days), and to fill in the diary twice a day, once in the morning directly after waking up and once in the evening directly before going to sleep. All students filled in the diary from a Monday morning to a Sunday evening. Adolescents who requested daily reminders to complete the diary were sent text messages twice a day. The researchers visited the school a second time after the study period to collect the diaries and watches from the adolescents. All adolescents who successfully filled in the diary and wore the actigraph watch for the full 7 days received a cinema ticket for their participation. This study was approved by Ghent University's ethical review board.

\section{Daily evening measures}

Daily need experiences. The daily satisfaction and frustration of adolescents' needs for autonomy, competence, and relatedness were assessed using a shortened version of the Basic Psychological Need Satisfaction and Need Frustration Scale (BPNSNFS; Chen et al., 2015), which is a crossculturally validated extension of the BMPN scale used in Study 1 . We chose to administer this shortened version, rather than the full 24-item scale, to limit participant burden. The shortened version proved valid in a previous study among elementary school children (Van der Kaap-Deeder et al., 2016) and consists of 12 items, four items per need, two of which tap into need satisfaction and two of which tap into need frustration. All participants rated on a scale of 1 (not at all true) to 5 (very true) as to whether they felt their needs for autonomy (e.g., "Today I felt that my decisions reflected what I really wanted" or "Today I felt forced to do things that I didn't choose to do"), competence (e.g., "Today I felt confident that I could do things well" or "Today I felt disappointed in my achievements"), and relatedness (e.g., "Today I felt connected with the people who care about me and who I care about" or "Today I felt excluded from the group that I want to belong to") were satisfied or frustrated during the past day. Six separate need scores were created by averaging the items assessing the satisfaction of the needs for autonomy, competence, and relatedness, as well as the items assessing the frustration of these needs. In addition, two need composite scores were created by computing the average of the three separate need satisfaction scores and by computing the average of the three separate need frustration scores. The composite scores of need satisfaction (within-person $\alpha=.73$, between-person $\alpha$ $=.92$ ) and need frustration (within-person $\alpha=.66$, betweenperson $\alpha=.94$ ) had acceptable reliability. Satisfaction of the need for autonomy (within-person $\alpha=.50$, between-person $\alpha$ $=.78$ ) had poor reliability at the within-person level. Satisfaction of the need for competence (within-person $\alpha=.61$, between-person $\alpha=.82$ ) and relatedness (within-person $\alpha=.69$, between-person $\alpha=.90$ ) had acceptable reliability. Frustration of the needs for autonomy (within-person $\alpha=.57$, between-person $\alpha=.97$ ), competence (within-person $\alpha=.54$, between-person $\alpha=.98$ ), and relatedness (within-person $\alpha=$ .64 , between-person $\alpha=.88$ ) had poor reliability at the within-person level.

Daily stress. Symptoms of stress were assessed using two items selected from the Stress subscale of the short-form version of the Depression Anxiety and Stress Scale (DASS; Lovibond \& Lovibond, 2004). The two items assessed the prevalence of two symptoms of stress during the past day (i.e., "Today I was very agitated" and "Today I noticed that I was very restless"). Participants rated both items on a scale from 1 (completely disagree) to 5 (completely agree). The symptoms of stress had good reliability (within-person $\alpha=.85$, between-person $\alpha=.97$ ).

Daily fatigue. Similar to Study 1, daily fatigue was assessed using the seven-item Lassitude subscale from the IDAS (Watson et al., 2007), which was adapted so that it tapped into experienced fatigue during the past day (e.g., "Today I felt exhausted"). All items were rated on a 5-point Likerttype scale ranging from 1 (not at all) to 5 (very much so). The scale had good reliability (within-person $\alpha=.75$, betweenperson $\alpha=.89$ ).

\section{Daily morning measures}

Daily subjective sleep quality. Also similar to Study 1, daily subjective sleep quality was assessed using a VAS from the Pittsburgh Sleep Diary (Monk et al., 1994), which assessed the previous night's subjective sleep quality (i.e., "How was your sleep quality last night?") on a scale from 0 (extremely poor) to 100 (extremely good).

Daily objective sleep quantity. To obtain an objective estimation of daily sleep quantity, participants were instructed to wear a MotionWatch 8 actigraph watch (Wave Medical B.V.; The Netherlands) on their nondominant arm for the duration of the study (i.e., for the full 7 days). The MotionWatch 8 is an unobtrusive, light-weight device worn on the wrist. The device includes a digital accelerometer, which measures movement, thereby allowing for the differentiation between probable wake and sleep states for each 30 -s period of recording. Participants were instructed to press the event marker button on the watch when they went to bed and when they got up in the morning, which inserted a marker in the actigraph recording. As per recommended guidelines (Sadeh, 2011), all objective actigraphy indicators were also assessed subjectively using self-reports (i.e., in the morning; Monk et al., 1994) so that any uncertainties arising from the actigraphy data could be cross-checked with the self-reported sleep diary data and adjusted accordingly if deemed appropriate. Daily sleep quantity was extracted from the actigraph data using the CamNtech MotionWare software (Version 
Table 2. Means, Standard Deviations, ICCs, and Within-Person Correlations Between Study Variables—Study 2.

\begin{tabular}{|c|c|c|c|c|c|c|c|c|c|c|c|c|c|c|}
\hline Study Variables & I & 2 & 3 & 4 & 5 & 6 & 7 & 8 & 9 & 10 & II & 12 & 13 & 14 \\
\hline $\begin{array}{l}\text { I. Need } \\
\text { satisfaction } \\
\text { composite }\end{array}$ & - & $.92^{* *}$ & $.89 * *$ & $.86 * *$ & $-.7 I^{* *}$ & $-.58 * *$ & $-.68 * *$ & $-.58 * *$ & $-.42 * *$ & $-.28 *$ & .27 & .03 & -.03 & -.06 \\
\hline $\begin{array}{l}\text { 2. Autonomy } \\
\text { satisfaction }\end{array}$ & $.85^{* *}$ & - & $.75^{* *}$ & $.71 * *$ & $-.59 * *$ & $-.56 * *$ & $-.56 * *$ & $-.40 * *$ & $-.33^{*}$ & -.19 & .17 & -.004 & -.001 & -.13 \\
\hline $\begin{array}{l}\text { 3. Competence } \\
\text { satisfaction }\end{array}$ & .81 ** & $.53^{* *}$ & - & $.64^{* *}$ & $-.63^{* *}$ & $-.42^{* *}$ & $-.72 * *$ & $-.49 * *$ & $-.44 * *$ & $-.33^{*}$ & .26 & .02 & .05 & -.02 \\
\hline $\begin{array}{l}\text { 4. Relatedness } \\
\text { satisfaction }\end{array}$ & $.79 * *$ & $.48^{* *}$ & $.49 * *$ & - & $-.68 * *$ & $-.59 * *$ & $-.53 * *$ & $-.69 * *$ & $-.36 * *$ & -.23 & $.30^{*}$ & .08 & -.13 & .01 \\
\hline $\begin{array}{l}\text { 5. Need } \\
\text { frustration } \\
\text { composite }\end{array}$ & $-.64^{* *}$ & $-.46^{* * *}$ & $-.54 * *$ & $-.58 * *$ & - & $.86 * *$ & $.91 * *$ & $.85^{* *}$ & $.65^{* *}$ & $.64^{* *}$ & $-.36 *$ & -.22 & .18 & .05 \\
\hline $\begin{array}{l}\text { 6. Autonomy } \\
\text { frustration }\end{array}$ & $-.48^{* *}$ & $-.4 I^{* *}$ & $-.33^{* *}$ & $-.43 * *$ & $.79 * *$ & - & $.65^{* *}$ & $.57^{* *}$ & $.63 * *$ & $.48^{* *}$ & $-.31 *$ & -.21 & .16 & .05 \\
\hline $\begin{array}{l}\text { 7. Competence } \\
\text { frustration }\end{array}$ & $-.57^{* *}$ & $-.39 * *$ & $-.60 * *$ & $-.43 * *$ & $.86^{* *}$ & $.48^{* * *}$ & - & $.70 * *$ & $.61^{* *}$ & $.65^{* *}$ & -.25 & -.22 & .06 & .04 \\
\hline $\begin{array}{l}\text { 8. Relatedness } \\
\text { frustration }\end{array}$ & $-.5 I^{* *}$ & $-.32 * *$ & $-.37^{* *}$ & $-.58 * *$ & $.78^{* *}$ & $.40 * *$ & $.58^{* *}$ & - & $.44 * *$ & $.56 * *$ & $-.38 * *$ & -.13 & $.30^{*}$ & .04 \\
\hline 9. Fatigue & $-.3 I^{* *}$ & $-.23 * *$ & $-.28 * *$ & $-.25 * *$ & $.48^{* *}$ & $.45^{* *}$ & $.42^{* *}$ & $.28^{* *}$ & - & $.60 * *$ & -.27 & $-.30 *$ & .18 & .12 \\
\hline 10. Stress & $-.25^{* *}$ & $-.14^{* *}$ & $-.28^{* *}$ & $-.20 * *$ & $.54 * *$ & $.34 * *$ & $.53 * *$ & $.44 * *$ & $.36 * *$ & - & $-.34 *$ & -.26 & .20 & .21 \\
\hline $\begin{array}{l}\text { II. Subjective } \\
\text { sleep quality }\end{array}$ & $.16^{* *}$ & .06 & $.14^{* *}$ & $.19 * *$ & $-.28^{* *}$ & $-.20 * *$ & $-.21^{* *}$ & $-.27^{* *}$ & $-.17^{* *}$ & $-.24 * *$ & - & .01 & -.20 & -.01 \\
\hline $\begin{array}{l}\text { 12. Objective } \\
\text { sleep quantity }\end{array}$ & .05 & .07 & .01 & .03 & $-.17^{* *}$ & $-.13^{* *}$ & $-.19 * *$ & -.08 & -.07 & $-.21^{* *}$ & $-.21 * *$ & - & -.18 & -.11 \\
\hline $\begin{array}{l}\text { 13. Objective } \\
\text { sleep latency }\end{array}$ & -.04 & -.01 & .02 & -.10 & .07 & .06 & -.002 & $.14^{* *}$ & .10 & .04 & -.06 & -.08 & - & $.32 *$ \\
\hline $\begin{array}{l}\text { 14. Objective } \\
\text { wake after sleep } \\
\text { onset }\end{array}$ & -.07 & -.13 & -.02 & -.02 & .004 & .01 & $-.00 \mathrm{I}$ & .01 & .03 & .09 & -.05 & $-.32 * *$ & $.15^{* *}$ & - \\
\hline$M$ & 3.48 & 3.19 & 3.41 & 3.84 & 2.09 & 2.39 & 2.32 & 1.58 & 2.40 & 2.19 & 71.99 & $4 \mid 5.77$ & 22.63 & 33.78 \\
\hline$S D$ & 0.73 & 1.00 & 0.85 & 0.85 & 0.78 & 1.01 & 1.03 & 0.83 & 0.85 & 1.19 & 19.26 & 60.24 & 29.37 & 10.04 \\
\hline ICC & .45 & .39 & .39 & .35 & .57 & .48 & .48 & .43 & .32 & .46 & .50 & .26 & .22 & .59 \\
\hline
\end{tabular}

Note. Within-person correlations are displayed below the diagonal and between-person correlations are displayed above the diagonal. ICC $=$ intraclass correlations.

$* p<.05 . * * p .01$.

1.1.25) validated algorithm. Although the Motionwatch 8 is a relatively new device, it has been shown to have good agreement with polysomnography-derived sleep parameters, which is generally deemed to be the gold standard for assessing sleep objectively (Elbaz et al., 2012). In addition, it has also been shown to be valid when tested against other actigraph devices (Morgan et al., 2012).

Plan of analysis. Given that these data also involved repeated measurements (i.e., Level 1), nested within 51 adolescents (i.e., Level 2), we performed multilevel analysis using Mplus 7 to test our proposed integrated models. There were $9 \%$ missing values in the data. Little's MCAR was nonsignificant (normed $\chi^{2}$ of 1.15), indicating that the data were likely to be missing at random. As a result, FIML was used to handle missing data in the two-level path models (Little \& Rubin, 1987).

Two 2-level path models were tested. In the first model, we examined whether stress would play an intervening role in the association between need experiences and sleep at the within-person (i.e., daily) level (i.e., Hypothesis 1), and in the second model, we examined the intervening role of daily fatigue and symptoms of stress in the relation between daily sleep and daily need-based experiences (i.e., Hypothesis 2). In each model, all predictor variables were centered around the group mean. Model fit was evaluated using the CFI, the RMSEA, and the SRMR. An acceptable fit was indicated by CFI values of 0.90 or above, and RMSEA and SRMR values of around 0.08 or below (Hu \& Bentler, 1999; Kline, 2005).

\section{Results}

\section{Preliminary analyses}

Correlations. The means, standard deviations, and correlations between all the assessed measures are shown in Table 2 . The within-person correlations indicated that the composite score of daily need satisfaction was negatively related to daily stress and daily fatigue, and was positively related to daily subjective sleep quality but was unrelated to daily objective sleep quantity. The composite score of daily need frustration displayed similar associations with the study variables but in the opposite direction. However, different to daily need satisfaction, daily need frustration was also 


$$
\begin{array}{ll}
\text { Evening measures } \quad \text { Morning measures }
\end{array}
$$

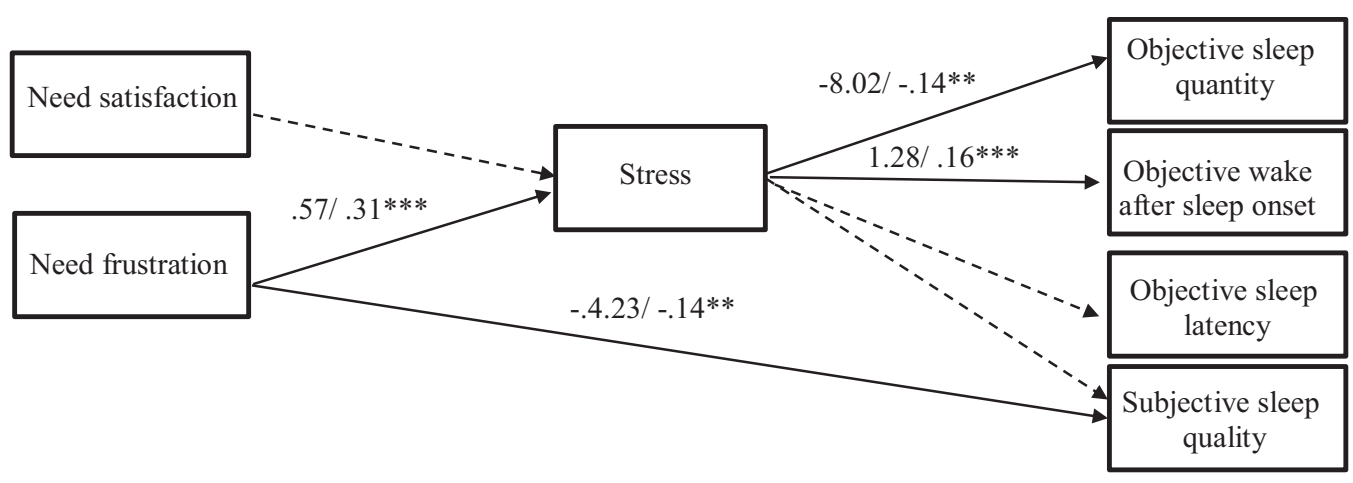

Figure 2. Daily need satisfaction and need frustration predicting daily subjective sleep quality and objective sleep outcomes via stressStudy 2.

Note. Coefficients before the line are unstandardized and coefficients after the line are standardized. Broken lines represent nonsignificant paths.

$*_{p}<.05 . *_{p}<.01 . *_{*} * 001$.

negatively related to daily objective sleep quantity. The within-person correlations indicated that the three individual need satisfactions and need frustrations were moderately to highly correlated and displayed a fairly similar pattern of relations with the study variables.

Background variables. To examine the relation between background characteristics and the study variables, a MANCOVA was performed with gender as a fixed factor, age as a covariate, and all study variables as dependent variables. For these analyses, all daily measures were aggregated across the 8 days. Gender, $F(6,43)=1.77, n s$, was unrelated to the study variables, whereas age yielded a significant multivariate effect, $F(6,43)=2.86, p<.05, \eta^{2}=.29$. Subsequent univariate analyses indicated that age was negatively related to daily objective sleep quantity, $F(1,48)=16.14, p<.01, \eta^{2}=.25$.

ICCs. The ICC values of all study variables are displayed in Table 2. Similar to results from Study 1, with regard to fatigue, stress, subjective sleep quality, and the objective sleep outcomes, the ICC values indicated that a significant proportion of the variance in these variables could be attributed to the within-person level, with objective sleep latency displaying the most amount of variance within individuals (i.e., approx. 78\%) and objective wake after sleep onset displaying the least amount of variance within individuals (i.e., approx. 41\%). Similar to findings from Study 1, ICC values indicated that approximately $55 \%$ and $43 \%$ of the variation in need satisfaction and need frustration, respectively, was situated within individuals.

\section{Primary analyses}

Hypothesis 1: Examining the intervening role of daily stress in the relation between daily need experiences and sleep.

To examine whether daily stress would play an intervening role in the association between daily need experiences and subjective sleep quality and the objective sleep indicators, we specified a two-level path model. First, direct paths were added at the within-person level (i.e., daily level) from the need composites ${ }^{3}$ (i.e., need satisfaction and need frustration) to the sleep indicators (subjective sleep quality, objective sleep quantity, objective sleep latency, and objective wake after sleep onset), which were allowed to correlate. In contrast to findings from Study 1, results from this model, $\mathrm{CFI}=0.98$, RMSEA $=0.03$, SRMR (within) $=0.01$, indicated that daily need frustration was negatively related to daily objective sleep quantity $(B=-15.41, \beta=-.15$, $S E=0.07, p<.05$; CI $95 \%=[-0.261,-0.046])$ and daily subjective sleep quality $(B=-4.29, \beta=-.15, S E=0.07$, $p<.05$; CI 95\% $=[-0.265,-0.029])$. All other associations were nonsignificant.

Next, we introduced stress into the model by adding paths from the need composites to stress, and from stress to the sleep indicators. Results from this model, CFI $=0.94$, RMSEA $=0.05$, SRMR (within) $=0.04$, indicated that daily need frustration was positively related to daily stress $(B=$ $0.57, \beta=.31, S E=0.08, p<.01$; CI 95\% $=[0.185,0.439])$, whereas daily need satisfaction was unrelated to same-day stress. Daily stress, in turn, was negatively related to daily objective sleep quantity $(B=-8.02, \beta=-.14, S E=0.05, p$ $<.01$; CI $95 \%=[-0.230,-0.058])$, and positively related to objective wake after sleep onset $(B=1.28, \beta=.16, S E=$ $0.04, p<.01$; CI 95\% $=[0.095,0.219])$, but was unrelated to objective sleep latency and daily subjective sleep quality. Direct paths were gradually added in between the predictor variables and the outcomes but were removed because they were nonsignificant, with the exception of the direct path between daily need frustration and subjective sleep quality $(B=-4.23, \beta=-.14, S E=0.06, p<.01$; CI $95 \%=$ $[-0.238,-0.049])$, which was significant. ${ }^{4}$ Results from this final integrative model, CFI $=0.96, \mathrm{RMSEA}=0.05, \mathrm{SRMR}$ 
$\begin{array}{lll}\text { Morning measures } & \text { Evening measures }\end{array}$

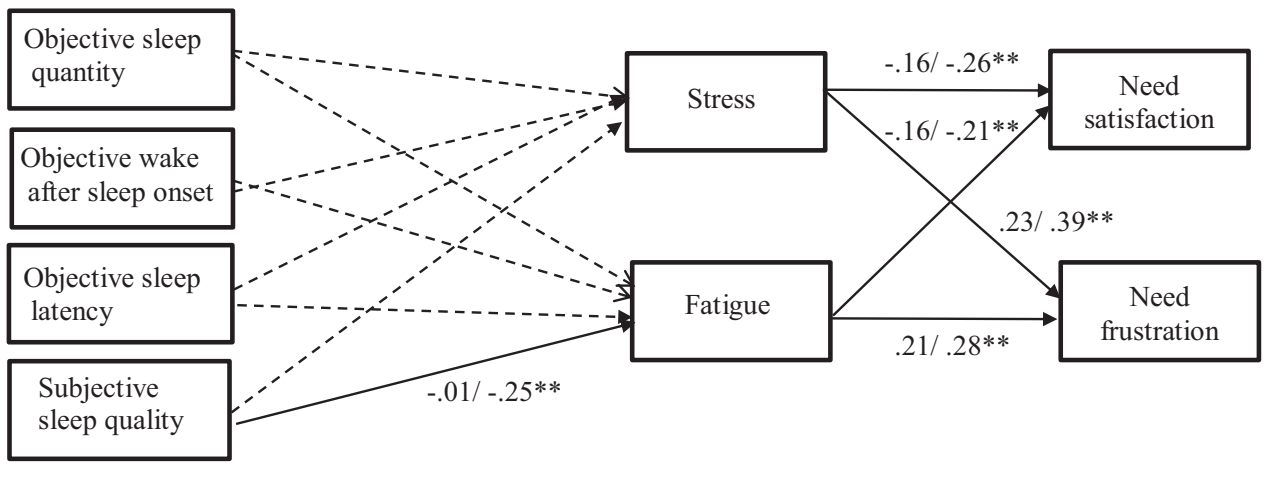

Figure 3. Daily subjective sleep quality and objective sleep indicators predicting daily need-based experiences via stress \& fatigue-Study 2 . Note. Coefficients before the line are unstandardized and coefficients after the line are standardized. Broken lines represent non-significant paths.

$*_{p}<.05 . * * p<.01 . * * * p<.001$.

(within $)=0.02$, are shown in Figure 2 . The indirect associations between daily need frustration and objective sleep quantity $(B=-4.58, S E=1.879, p<.01$; CI $95 \%=$ $[-7.670,-1.489])$, and objective wake after sleep onset $(B=0.73, S E=0.211, p<.01 ;$ CI $95 \%=[1.076,0.381])$, via daily stress was significant.

Next, we tested an additional model in which we controlled for previous day levels of stress and the four sleep outcomes (i.e., subjective sleep quality, objective sleep quantity, objective sleep latency, and objective wake after sleep onset). Results of this more conservative model (see Figure S2 in the Supplemental Material) indicated that all day-today associations remained significant, except for the association between daily stress and daily objective wake after sleep onset.

Hypothesis 2: The role of daily subjective sleep quality and objective sleep indicators in predicting need experiences via fatigue and stress.

In a next model, we examined whether daily subjective sleep quality and the objective sleep indicators would relate to daily need experiences via fatigue and symptoms of stress. First, we tested a direct effect model by specifying a twolevel path model and adding paths at the within-person level (i.e., daily level) from subjective sleep quality and the objective sleep indicators to daily need satisfaction and need frustration. Results of this model, CFI $=0.90$, RMSEA $=0.20$, SRMR (within) $=0.003$, indicated that daily sleep quality was uniquely negatively related to daily need frustration $(B=-0.01, \beta=-.13, S E=0.05, p<.01$; CI $95 \%=$ $[-0.219,-0.045])$.

Next, we introduced fatigue and stress into the model as intervening variables by adding paths from the sleep indicators to fatigue and stress, and from fatigue and stress to the need composite scores. As shown in Figure 3, results from this model, $\mathrm{CFI}=0.85, \mathrm{RMSEA}=0.17$, SRMR (within) $=0.01$, indicated that subjective sleep quality was negatively related to fatigue $(B=-0.01, \beta$ $=-.25, S E=0.05, p<.01$; CI 95\% $=[-0.338$, $-0.159])$, whereas the other sleep indicators were unrelated to fatigue. Fatigue, in turn, was negatively related to need satisfaction $(B=-0.16, \beta=-.21, S E=0.06, p<$ .01 ; CI $95 \%=[-0.288,-0.096])$, and positively related to need frustration $(B=0.21, \beta=.28, S E=0.05, p<$ .01 ; CI $95 \%=[0.176,0.349])$. Of note, the paths between all of the four sleep indicators and symptoms of stress were nonsignificant. However, stress was negatively related to need satisfaction $(B=-0.16, \beta=-.26, S E$ $=0.04, p<.01$; CI 95\% $=[-0.374,-0.155])$, and positively related to need frustration $(B=0.23, \beta=.39, S E=$ $0.04, p<.01$; CI $95 \%=[0.292,0.485])$. Direct paths were gradually added into the model between the predictors (i.e., subjective sleep quality and objective sleep quantity) and the outcomes (i.e., need satisfaction and need frustration), but were nonsignificant. ${ }^{5}$ The indirec associations between subjective sleep quality and need satisfaction $(B=0.002, S E=0.001, p<.01$; CI $95 \%$ $=[0.000,0.000])$ and need frustration $(B=-0.003, S E=$ $0.001, p<.01$; CI $95 \%=[0.000,0.000])$, via fatigue, were significant.

Next, we tested a model in which we controlled for previous day levels of the intervening variables (i.e., fatigue and symptoms of stress) and need experiences (i.e., need satisfaction and need frustration). Results of this model (see Figure S3 in the Supplemental Material) revealed that after controlling for these previous day covariates, all previously observed associations at the within-person level remained significant. 


\section{Brief Discussion}

The results from Study 2 only partially confirm those reported in Study 1. Specifically, different from Study 1, daily variation in need frustration (but not in need satisfaction) related positively to daily variation in symptoms of stress, which in turn contributed to shorter objective sleep quantity at night as well as more objectively assessed awakenings throughout the night. Daily need frustration was also directly related to poorer daily subjective sleep quality. Follow-up analyses, controlling for the previous day levels of stress and the sleep outcomes, indicated that most of these associations stand. Specifically, daily need frustration on a given day contributed to a decrease in subjective sleep quality and objective sleep quantity during the subsequent night compared to the night before, with the latter occurring via an increase in daily symptoms of stress on that day compared with the previous day.

In terms of the sleep to needs relation, poorer daily subjective sleep quality was related to experiencing more fatigue throughout the day, which in turn contributed to less daily need satisfaction and more daily need frustration. These dayto-day associations remained significant after controlling for previous day levels of fatigue and the need-based experiences, indicating that poor subjective sleep quality contributed to an increase in need frustration from one day to the other via an increase in daily fatigue.

\section{General Discussion}

Although sleep disturbances in adolescence are highly prevalent (Gradisar et al., 2011) and have consistently been linked to poor adolescent functioning (Shochat et al., 2014), few studies have identified psychological predictors of day-to-day variability in adolescent sleep. In line with previous diary studies (e.g., Doane \& Thurston, 2014; Fuligni \& Hardway, 2006; Galambos et al., 2009), the present findings demonstrated that adolescent sleep outcomes fluctuate considerably from day-to-day. Importantly, the present research extended previous findings by examining whether the satisfaction and frustration of the basic psychological needs for autonomy, competence, and relatedness would contribute to this day-to-day variability in adolescent sleep, as well as whether day-to-day variability in sleep would contribute to adolescents' daily need experiences via daily fluctuations in fatigue and symptoms of stress. Furthermore, the role of stress in the day-to-day need-sleep association was also examined. A number of important findings emerged.

\section{The Role of Daily Need Experiences in Predicting Daily Sleep}

With regard to the role of daily need experiences in predicting adolescent sleep outcomes, the results were variable across both studies. In Study 1, daily fluctuations in needbased experiences did not appear to predict day-to-day variation in adolescent self-reported sleep outcomes. In contrast, in Study 2, which moved to assessing quantitative sleep indicators objectively via wrist actigraphy, a different pattern of results emerged. Namely, daily need frustration was found to contribute to shorter objectively assessed daily sleep quantity through higher daily symptoms of stress, suggesting that stress plays an intervening role in this day-to-day association. This pattern of findings is similar to previous findings obtained in a clinical sample, which found between-person differences in need frustration to only be indirectly (and not directly) related to objective and subjective sleep outcomes via symptoms of stress and negative sleep-related cognitions (Campbell et al., 2017). Further research is needed to understand why, in some cases, need-based experiences are directly related to sleep outcomes (e.g., Campbell et al., 2015, 2019; Campbell, Vansteenkiste, et al., 2018), and in other cases, they are only indirectly related to sleep indicators via intervening variables (Campbell et al., 2017).

The need-sleep association at the within-person level in Study 2 appeared robust as the association between daily need frustration and daily objective sleep quantity even remained significant after controlling for the previous day's amount of sleep, indicating that need frustration contributes to a reduction in daily sleep quantity. This finding is consistent with previous findings among college students, which similarly found within-person increases in need frustration to relate to within-person reductions in sleep quantity (Campbell, Soenens, Beyers, \& Vansteenkiste, 2018). Findings from Study 2 further indicated that daily need frustration also related to poorer daily subjective sleep quality. Of note, this direct negative association between daily need frustration and daily subjective sleep quality was not accounted for by daily symptoms of stress and remained significant after controlling for the stability in subjective sleep quality. This suggests that need frustration contributed to a deterioration in self-reported sleep quality, but stress cannot account for this finding, at least in this study. These results differ from findings from previous studies carried out among college students (Campbell, Soenens, Beyers, \& Vansteenkiste, 2018) and clinical (Campbell et al., 2017) samples, which found need frustration to relate to poorer subjective sleep quality, with symptoms of stress accounting for this link. Future research is needed to replicate these findings and shed further light on the (non)explanatory role of stress in the adolescent need-sleep quality dynamic.

Although the findings were not consistent across studies, the results from Study 2 underscore the critical maladaptive role of experiences of need frustration as it appeared that the active frustration of psychological needs obstructed adolescent sleep. It was the active undermining rather than merely the absence of need satisfaction that was found to leave adolescents vulnerable for poorer sleep. In documenting this finding, the present research extends previous research 
among adolescents, which found need frustration to confer risk of internalizing and externalizing problem behaviors (Costa et al., 2016; Mabbe et al., 2016). Overall, the present findings add to a growing body of empirical research (e.g., Bartholomew et al., 2011; Cordeiro et al., 2016; Van der Kaap-Deeder et al., 2016), which indicates that psychological need satisfaction and need frustration are distinct constructs with differential outcomes, with need frustration being especially predictive of ill-being, over and above a lack of need satisfaction.

\section{The Role of Daily Sleep in Predicting Daily Need Experiences}

Given the likely reciprocal relation between daily need experiences and sleep, in both studies we also examined the role of daily adolescent sleep in predicting daily need experiences. In Study 1, results revealed that shorter selfreported daily sleep quantity related to more fatigue, which in turn related to less need satisfaction and more need frustration throughout the day. In addition, longer self-reported sleep latency also related to more need frustration the following day. These associations remained significant after controlling for the previous days' need experiences, suggesting that shorter sleep quantity yielded a fatigue-exacerbating effect, which in turn explained subsequent decreases in need satisfaction and increases in need frustration, whereas longer self-reported sleep latency directly contributed to an increase in need frustration across days.

Results from Study 2 only partially replicated the findings observed in Study 1. Specifically, in Study 2, poorer selfreported sleep quality at night related to more fatigue throughout the following day, which in turn interfered with daily need experiences, whereas objective sleep quantity was unrelated to daily fatigue and daily need experiences. Of note, in Study 2, only daily fatigue, and not symptoms of stress, was found to account for the association between sleep quality and the need-based experiences. Thus, in Study 2 , it appeared that adolescents' symptoms of stress were rooted in daily need-based experiences rather than daily adolescent sleep.

Overall, these results suggest that daily need frustration and the daily sleep outcomes appear to be reciprocally related via intervening variables. However, the pathways through which they relate to one another are different, with higher daily symptoms of stress explaining why daily need frustration obstructs sleep quantity at night and higher daily fatigue explaining why poor sleep at night interferes with daily need experiences. Together, these results suggest that adolescents who experience either daily need frustration or poor sleep at night may be at risk of becoming trapped in a vicious negative cycle.

\section{Limitations and Suggestions for Future Research}

The present research has several limitations. First, the samples used in both studies were fairly homogeneous, which limits the generalizability of the findings. Future research is needed to replicate these findings among adolescents from more diverse socioeconomic and cultural backgrounds. Furthermore, it would also be interesting to examine whether these findings extend to adolescents with a clinically diagnosed sleep disorder. Second, the use of self-reports to assess sleep quality may have inflated the observed association between daily need frustration and daily subjective sleep quality in Study 2 through shared method variance. Future research could try to overcome this problem by using alternative objective measures of sleep such as polysomnography to provide an indication of sleep quality (Scholle et al., 2011).

The satisfaction and frustration of the individual needs for autonomy, competence, and relatedness had low reliability at the facet level (ranging from $\alpha=.49-.76$ ). Low reliabilities at the need facet level were similarly observed in a study among adolescents that examined need experiences from week to week, with reliabilities ranging from $\alpha=.53$ to .75 (Vandenkerckhove et al., 2019), and might perhaps be due to the fact that covariances at the within-person level may be heterogeneous across people (Nezlek, 2017). Furthermore, according to Geldhof et al. (2014), withinlevel estimates may be untrustworthy when clusters are small (though this condition may be more applicable to dyadic data). Alternatively, the relatively low internal consistencies at the within-person level may be because the different items in each of the subscales that tap into the satisfaction or frustration of a particular need may not necessarily co-occur on the same day or even in the same week. Although an adolescent might feel excluded from a group that they would like to belong to on a given day (relatedness frustration), they may not necessarily feel that the people most important to them were cold and distant toward them on that same day (lack of relatedness frustration). This issue of how the individual items that tap into the need satisfactions and frustrations covary within individuals from day-to-day, relative to across individuals, over larger time frames should be explored in future research.

As a result of the low reliabilities at the facet level, the findings with regard to the unique role of the individual needs in the reciprocal need-sleep associations should be interpreted with caution (see Supplemental Material for detailed results). It should also be noted that when examined at the facet level, the pattern of unique associations between the three needs and the outcomes was not very systematic. Given the lack of uniformity and the fact that this is the first study to examine these associations among adolescents, it seems too early to speculate as to why this is. More research in both nonclinical and clinical adolescent samples is needed to address this issue. 
Although these results suggest that psychological need frustration and sleep are reciprocally related, future experimental research is needed to shed more light on these causal pathways. For example, future experimental research could try to induce feelings of need satisfaction or need frustration among adolescents (e.g., Weinstein et al., 2016), and examine whether this affects their quality and quantity of sleep at night. Alternatively, experimental research could also induce sleep fragmentation (e.g., Finan et al., 2015) within participants to more closely examine the impact of poor sleep on daily need experiences. In addition, future studies could also perform a more conservative test of these associations by examining whether daily need frustration predicts daily stress and sleep outcomes over and above other variables such as daily negative affect. Furthermore, given that the present research only used two items that tapped into physiological arousal to assess symptoms of stress, future research should use a broader range of items to assess daily stress that also capture perceptions of being overwhelmed or overly taxed by demands (Cohen et al., 1983). Finally, future research should also seek to identify moderators of the dayto-day association between psychological need experiences, stress, and adolescent sleep. For example, future studies could examine the moderating role of adolescents' dispositional mindfulness (Brown \& Ryan, 2003) or self-critical perfectionism (Blatt, 2004), as both have previously been shown to influence stress reactivity (e.g., Bekes et al., 2015; Weinstein et al., 2009).

\section{Conclusion}

In sum, the present research provides the first evidence for a dynamic reciprocal interplay between adolescents' need experiences and sleeping pattern. Overall, results revealed that on days that adolescents feel pressured and ineffective in their activities and disconnected from important others, they are more likely to experience poorer sleep as a result of increased daily stress. Results further suggest that after a night of poor sleep, adolescents are more likely to feel drained of energy, which may prevent their effective engagement in need-satisfying activities. These results imply that adolescents should be helped to both recognize and minimize sources of need frustration within their daily life to avoid symptoms of stress and poor sleep. In addition, adolescents should also be encouraged to engage in healthy sleep behaviors, given that poor sleep can also contribute to reduced need satisfaction.

\section{Declaration of Conflicting Interests}

The author(s) declared no potential conflicts of interest with respect to the research, authorship, and/or publication of this article.

\section{Funding}

The author(s) disclosed receipt of the following financial support for the research, authorship, and/or publication of this article: This work was supported by the Fund for Scientific Research Flanders (FWO.OPR.2013. 0140.01-IV2).

\section{ORCID iD}

Rachel Campbell (D) https://orcid.org/0000-0002-5013-8361

\section{Supplemental Material}

Supplemental material for this article is available online.

\section{Notes}

1. The results from the models examining the individual need satisfactions and frustrations are available in the Supplemental Material.

2. At the within-person level, fatigue accounted for $60 \%$ of the original direct effect between sleep quantity and need frustration.

3. Results from the models that include each individual need (i.e., for autonomy, competence, and relatedness) are provided in the supplemental material.

4. Daily symptoms of stress accounted for $62 \%$ of the original direct effect between daily need frustration and daily objective sleep quantity.

5. Daily fatigue accounted for $77 \%$ of the original direct effect between daily subjective sleep quality and daily need frustration.

\section{References}

Bartholomew, K. J., Ntoumanis, N., Ryan, R. M., \& ThøgersenNtoumani, C. (2011). Psychological need thwarting in the sport context: Assessing the darker side of athletic experience. Journal of Sport \& Exercise Psychology, 33, 75-102.

Becker, S. P., Langberg, J. M., \& Byars, K. C. (2015). Advancing a biospychosocial and contextual model of sleep in adolescence: A review and introduction to the special issue. Journal of Youth and Adolescence, 44, 239-270.

Bekes, V., Dunkley, D. M., Taylor, G., Zuroff, D. C., Lewkowski, M., Foley, J. E., Myhr, G., \& Westreich, R. (2015). Chronic stress and attenuated improvement in depression over 1 year: The moderating role of perfectionism. Behavior Therapy, 46, 478-492.

Blatt, S. J. (2004). Experiences of depression: Theoretical, clinical and research perspectives. American Psychological Association.

Bolger, N., Davis, A., \& Rafaeli, E. (2003). Diary methods: Capturing life as it is lived. Annual Review of Psychology, 54, 579-616.

Boone, L., Vansteenkiste, M., Soenens, B., van der KaapDeeder, J., \& Verstuyf, J. (2014). Self-critical perfectionism and binge eating symptoms: A longitudinal test of the intervening role of psychological need frustration. Journal of Counseling Psychology, 61, 363-373.

Brown, K. W., \& Ryan, R. M. (2003). The benefits of being present: Mindfulness and its role in psychological well-being. Journal of Personality and Social Psychology, 84, 822-848. https://doi.org/ 10.1037/0022-3514.84.4.822

Campbell, R., Soenens, B., Beyers, W., \& Vansteenkiste, M. (2018). University students' sleep during an exam period: The role of basic psychological needs and stress. Motivation and Emotion, 42, 671-681. 
Campbell, R., Soenens, B., Weinstein, N., \& Vansteenkiste, M. (2018). Impact of partial sleep deprivation on psychological functioning: Effects on mindfulness and basic psychological need satisfaction. Mindfulness, 9, 1123-1133.

Campbell, R., Tobback, E., Delesie, L., Vogelaers, D., Mariman, A., \& Vansteenkiste, M. (2017). Basic psychological need experiences, fatigue, and sleep in individuals with unexplained chronic fatigue. Stress \& Health, 33, 645-655.

Campbell, R., Vansteenkiste, M., Delesie, L., Tobback, E., Mariman, A., \& Vogelaers, D. (2018). Reciprocal associations between daily need-based experiences, energy, and sleep in chronic fatigue syndrome. Health Psychology, 37, 1168-1178.

Campbell, R., Vansteenkiste, M., Delesie, L. M., Mariman, A. N., Soenens, B., Tobback, E., Van der Kaap-Deeder, J., \& Vogelaers, D. P. (2015). Examining the role of psychological need satisfaction in sleep: A self-determination theory perspective. Personality and Individual Differences, 77, 199-204.

Campbell, R., Vansteenkiste, M., Delesie, L. M., Soenens, B., Tobback, E., Vogelaers, D., \& Mariman, A. (2019). The role of psychological need satisfaction, sleep, and mindfulness in the health related quality of life of people living with HIV. Journal of Health Psychology, 24, 535-545.

Chen, B., Vansteenkiste, M., Beyers, W., Boone, L., Deci, E. L., Duriez, B., Lens, W., Matos, L., Mouratidis, A., Ryan, R. M., Sheldon, K. M., Soenens, B., Van Petegem, S., Van der KaapDeeder, J., \& Verstuyf, J. (2015). Basic psychological need satisfaction, need frustration, and need strength across four cultures. Motivation and Emotion, 39, 216-236.

Cohen, S., Kamarck, T., \& Mermelstein, R. (1983). A global measure of perceived stress. Journal of Health and Social Behavior, 24, 385-396.

Cordeiro, P., Paixao, P., Lens, W., Lacante, M., \& Luyckx, K. (2016). The Portuguese validation of the basic psychological need satisfaction and frustration scale: Concurrent and longitudinal relations to well-being and ill-being. Psychologica Belgica, 56(3), 193-209.

Costa, S., Cuzzocrea, F., Gugliandolo, M. C., \& Larcan, R. (2016). Associations between parental psychological control and autonomy support, and psychological outcomes in adolescents: The mediating role of need satisfaction and need frustration. Child Indicators Research, 9(4), 1059-1076.

Dahl, R. E., \& Lewin, D. S. (2002). Pathways to adolescent health sleep regulation and behavior. Journal of Adolescent Health, 31, 175-184.

Deci, E. L., \& Ryan, R. M. (2000). The "what" and "why” of goal pursuits: Human needs and the self determination of behavior. Psychological Inquiry, 11, 227-268.

Doane, L. D., \& Thurston, E. C. (2014). Associations among sleep, daily experiences, and loneliness in adolescence: Evidence of moderating and bidirectional pathways. Journal of Adolescence, 37, 145-154.

Elbaz, M., Yauy, K., Metlaine, A., Martoni, M., \& Leger, D. (2012). Validation of a new actigraph motion watch versus polysomnography on 70 healthy and suspected sleepdisordered subjects. Journal of Sleep Research, 21(Suppl. 1), Article 218.

Emery, A. A., Toste, J. R., \& Heath, N. L. (2015). The balance of intrinsic need satisfaction across contexts as a predictor of depressive symptoms in children and adolescents. Motivation and Emotion, 39, 753-765.

Finan, P. H., Quartana, P. J., \& Smith, M. T. (2015). The effects of sleep continuity disruption on positive mood and sleep architecture in healthy adults. Sleep, 38, 1735-1742.

Fuligni, A. J., \& Hardway, C. (2006). Daily variation in adolescents' sleep, activities, and psychological well-being. Journal of Research on Adolescence, 16, 353-377.

Galambos, N. L., Dalton, A. L., \& Maggs, J. L. (2009). Losing sleep over it: Daily variation in sleep quantity and quality in Canadian students' first semester of university. Journal of Research on Adolescence, 19, 741-761.

Galambos, N. L., Howard, A. L., \& Maggs, J. L. (2010). Rise and fall of sleep quantity and quality with student experiences across the first year of university. Journal of Research on Adolescence, 21, 342-349.

Geldhof, G. J., Preacher, K. J., \& Zyphur, M. J. (2014). Reliability estimation in a multilevel confirmatory factor analysis framework. Psychological Methods, 19, 72-91.

Gradisar, M., Gardner, G., \& Dohnt, H. (2011). Recent worldwide sleep patterns and problems during adolescence: A review and meta-analysis of age, region, and sleep. Sleep Medicine, 12, 110-118.

Granic, I., Hollenstein, T., Dishion, T. J., \& Patterson, G. R. (2003). Longitudinal analysis of flexibility and reorganization in early adolescence: A dynamic systems study of family interactions. Developmental Psychology, 39, 606-617.

Heisel, A., Pietrek, A., Flunger, B., Fydrich, T., Rapp, M., Heinzel, S., \& Vansteenkiste, M. (2018). The validation of the German Basic Psychological Need Satisfaction and Frustration Scale in the context of mental health. European Journal of Health Psychology, 25, 119-132.

Hisler, G. C., Krizan, Z., \& DeHart, T. (2019). Does stress explain the effect of sleep on self-control difficulties? A month-long daily diary study. Personality and Social Psychology Bulletin, 45(6), 864-877.

Hu, L., \& Bentler, P. M. (1999). Cutoff criteria for fit indexes in covariance structure analysis: Conventional criteria versus new alternatives. Structural Equation Modeling, 6, 1-55.

Kline, R. B. (2005). Principles and practice of structural equation modeling. Guilford Press.

Krijgsman, C., Vansteenkiste, M., van Tartwijk, J., Maes, J., Borghouts, L., Cardon, G., Mainhard, T., \& Haerens, L. (2017). Performance grading and motivational functioning and fear in physical education: A self-determination theory perspective. Learning and Individual Differences, 55, 202-211. 
Larson, R. W., Moneta, G., Richards, M. H., \& Wilson, S. (2002). Continuity, stability, and change in daily emotional experience across adolescence. Child Development, 73, 1151-1165.

Levine, M., \& Ensom, M. H. (2001). Post hoc power analysis: An idea whose time has passed? Pharmacotherapy, 21, 405-409.

Little, R. J. A., \& Rubin, D. B. (1987). Statistical analysis with missing data. John Wiley.

Lovibond, S. H., \& Lovibond, P. F. (2004). Manual for the depression anxiety stress scales (2nd ed.). Psychology Foundation.

Mabbe, E., Soenens, B., Vansteenkiste, M., \& Van Leeuwen, K. (2016). Do personality traits moderate relations between psychologically controlling parenting and problem behavior in adolescents? Journal of Personality, 84, 381-392.

Maciejewski, D. F., Lier, P. A., Branje, S. J., Meeus, W. H., \& Koot, H. M. (2015). A 5-year longitudinal study on mood variability across adolescence using daily diaries. Child Development, 86, 1908-1921.

Miller, K., Danner, F., \& Staten, R. (2008). Relationship of work hours with selected health behaviors and academic progress among a college student cohort. Journal of American College Health, 56, 675-679.

Monk, T. H., Reynolds, C. F., Kupfer, D. J., Buysse, D. J., Coble, P. A., Hayes, A. J., Machen, M. A., Petrie, S. R., \& Ritenour, A. M. (1994). The Pittsburgh sleep diary. Journal of Sleep Research, 3, 111-120.

Morgan, P. L., Hampton, S., Karatziotou, A., Zaslona, J., \& Middleton, B. (2012). Validation of two new activity monitors: Motionwatch 8 and pro-diary motion. Journal of Sleep Research, 21(Suppl. 1), 217-218.

Nezlek, J. B. (2017). A practical guide to understanding reliability in studies of within-person variability. Journal of Research in Personality, 69, 149-155.

Roberts, R. E., Roberts, C. R., \& Xing, Y. (2011). Restricted sleep among adolescents: Prevalence, incidence, persistence, and associated factors. Behavioral Sleep Medicine, 9, 18-30.

Ryan, R. M., Bernstein, J. H., \& Brown, K. W. (2010). Weekends, work, and well-being: Psychological need satisfactions and day of the week effects on mood, vitality, and physical symptoms. Journal of Social and Clinical Psychology, 29, 95-122.

Ryan, R. M., \& Deci, E. L. (2008). From ego depletion to vitality: Theory and findings concerning the facilitation of energy available to the self. Social and Personality Psychology Compass, 2(2), 702-717.

Ryan, R. M., \& Deci, E. L. (2017). Self-determination theory: Basic psychological needs in motivation, development, and wellness. Guilford Press.

Ryan, R. M., Deci, E. L., \& Vansteenkiste, M. (2016). Autonomy and autonomy disturbances in self-development and psychopathology: Research on motivation, attachment, and clinical process. In D. Cicchetti (Ed.), Developmental psychopathology (3rd ed., pp. 385-438). John Wiley.

Sadeh, A. (2011). The role and validity of actigraphy in sleep medicine: An update. Sleep Medicine Reviews, 15, 259-267.

Scholle, S., Beyer, U., Bernhard, M., Eichholz, S., Erler, T., Graness, P., Goldmann-Schnalke, B., Heisch, K., Kirchhoff, F.,
Klementz, K., Koch, G., Kramer, A., Schmidtlein, C., Schneider, B., Walther, B., Wiater, A., \& Scholle, H. C. (2011). Normative values of polysomnographic parameters in childhood and adolescence: Quantitative sleep parameters. Sleep Medicine, 6, 542-549.

Sheldon, K. M., \& Hilpert, J. C. (2012). The Balanced Measure of Psychological Needs (BMPN) scale: An alternative domain general measure of need satisfaction. Motivation and Emotion, 4, 439-451.

Shochat, T., Cohen-Zion, M., \& Tzischinsky, O. (2014). Functional consequences of inadequate sleep in adolescents: A systematic review. Sleep Medicine Reviews, 18, 75-87.

Smith, C. V. (2007). In pursuit of "good" sex: Self-determination and sexual experience. Journal of Social and Personal Relationships, 24, 69-85.

Tremaine, R. B., Dorrian, J., \& Blunden, S. (2010). Subjective and objective sleep in children and adolescents: Measurement, age, and gender differences. Sleep and Biological Rhythms, 8, 229-238.

Vandenkerckhove, B., Soenens, B., Van der Kaap-Deeder, J., Brenning, K., Luyten, P., \& Vansteenkiste, M. (2019). The role of weekly need-based experiences and self-criticism in predicting weekly academic (mal)adjustment. Learning and Individual Differences, 69, 69-83.

Van der Kaap-Deeder, J., Vansteenkiste, M., Soenens, B., \& Mabbe, E. (2016). Children's daily well-being: The role of mothers', teachers', and siblings' autonomy support and psychological control. Developmental Psychology, 53(2), 237-251.

Vansteenkiste, M., \& Ryan, R. M. (2013). On psychological growth and vulnerability: Basic psychological need satisfaction and need frustration as a unifying principle. Journal of Psychotherapy Integration, 23, 263-280.

Vansteenkiste, M., Ryan, R. M., \& Soenens, B. (in press). Basic psychological need theory: Recent advancements, trends, and future directions. Motivation and Emotion, 44, 1-31.

Véronneau, M. H., Koestner, R. F., \& Abela, J. R. (2005). Intrinsic need satisfaction and well-being in children and adolescents: An application of the self-determination theory. Journal of Social and Clinical Psychology, 24, 280-292.

Verstuyf, J., Vansteenkiste, M., Soenens, B., Boone, L., \& Mouratidis, A. (2013). Daily ups and downs in women's binge eating symptoms: The role of basic psychological needs, general selfcontrol, and emotional eating. Journal of Social and Clinical Psychology, 32, 335-361.

Watson, D., O’Hara, M. W., Simms, L. J., Kotov, R., \& Chmielewski, M. (2007). Development and validation of the Inventory of Depression and Anxiety Symptoms (IDAS). Psychological Assessment, 19, 253-268.

Weinstein, N., Brown, K. W., \& Ryan, R. M. (2009). A multimethod examination of the effects of mindfulness on stress attribution, coping, and emotional well-being. Journal of Research in Personality, 43, 374-385.

Weinstein, N., Khabbaz, F., \& Legate, N. (2016). Enhancing need satisfaction to reduce psychological distress in Syrian refugees. Journal of Consulting and Clinical Psychology, 84, 645-650. 
Weinstein, N., \& Ryan, R. M. (2011). A self-determination theory approach to understanding stress incursion and responses. Stress and Health, 27, 4-17.

Yap, Y., Slavish, D. C., Taylor, D. J., Bei, B., \& Wiley, J. F. (2019). Bi-directional relations between stress and self-reported and actigraphy-assessed sleep: A daily intensive longitudinal study.
Sleep, 43(3), Article zsz250. https://doi.org/10.1093/sleep/ zsz250

Zhou, H. Q., Shi, W. B., Wang, X. F., Yao, M., Cheng, G. Y., Chen, P. Y., \& Li, D. G. (2012). An epidemiological study of sleep quality in adolescents in South China: A school-based study. Child: Care, Health and Development, 38, 581-587. 